\title{
Prevalence of Asthma in School going Children of Semi-Urban Area in the State of Madhya Pradesh
}

\author{
Athavale Arvind Vyankatesh, Patil Sandip Bharat, Agrawal Kush
}

\begin{abstract}
Introduction: Childhood asthma is the common chronic illness among school going children and is reportedly under diagnosed and undertreated. Rise in prevalence of childhood asthma is a matter of concern worldwide and in India also. Objectives: To estimate the prevalence of asthma among school children of 7th and 8th standard in semi-urban area of Bhopal and to find the association of various factors with asthma in the study population. Material and methods: This is a cross-sectional questionnaire based study, done among school going children of 7th and 8th standard, in the semiurban area of Bhopal. Questionnaire was based on that used by International Study of Asthma and Allergies in Childhood (ISSAC). Results: The prevalence of questionnaire diagnosed asthma among 331 school going children studied was found out to be $13.9 \%$. Out of this majority i.e. around $87 \%$ were newly diagnosed asthmatics. Out of the various factors examined for association with asthma, family history of asthma, history of allergy and cough without cold were found to be significantly associated. Females were having more prevalence as that of males and the ratio being 1:1.5 (male: female). Other variables such as pets at home, environmental tobacco smoke, and absence of chimney for smoke did not show any statistically significant association with the study. Conclusions: The study confirms the higher trend of asthma prevalence as depicted by various studies.
\end{abstract}

Key words: School, Child, Asthma, India, Prevalence, Risk factors.

\section{INTRODUCTION}

Childhood asthma is the common chronic illness among school going children and is reportedly under diagnosed and undertreated. ${ }^{1}$ Increase in the rates of hospital admission and primary care contacts for asthma in childhood has led to concern regarding prevalence or severity of increasing wheezing illness in children. Rise in prevalence of childhood asthma is a matter of concern worldwide and in India also. ${ }^{2-5}$ The steady rise in prevalence is correlated with demographic changes in city like increase in number of industries, increased density of population from migration of rural population and increased number of automobiles to commute resulting in air pollution. ${ }^{5}$ Data on prevalence of asthma is now available from several countries. There is very limited data on asthma epidemiology from the developing countries including India. But, few Indian studies have reported prevalence of childhood asthma ranging from $3.5 \%$ to 29.5. Diagnosis of asthma is often missed or delayed due to the dynamic nature of the disease, unreliable past history or poor documentation of past episodes or lack of specific and relative diagnostic investigation. ${ }^{6}$ Children with poorly controlled, untreated or under diagnosed asthma can have problems, as exercise induced bronco spasm (EIB) can leave them breathless and unable to participate or sometimes it could be dangerous. ${ }^{3}$ In this regard training of the school teachers with health guides may be one of the most important strategies for promotion of school health. ${ }^{7}$ There is no data available regarding prevalence of asthma in school children in the state of Madhya Pradesh.

\section{OBJECTIVES}

To estimate the prevalence of asthma among school children of $7^{\text {th }}$ and $8^{\text {th }}$ standard in semi-urban area of Bhopal.

To find the association of various factors with asthma in the study population.

\section{METHODOLOGY}

\section{Study design \& Settings}

It is a cross-sectional study which was done in all five higher secondary schools in Bairagarh area of Bhopal, Madhya Pradesh namely 1) Govt. Boys Middle School No.2, Bairagarh. 2) Govt. Jaslok Girls Middle School, Bairagarh. 3) Govt. Middle School No.1, Bairagarh. 4) Govt. Middle school No.2, C.T.O. Bairagarh. 5) Govt. Middle School, Bairagarh kala.

\section{Subjects \& Sample Size}

All the $7^{\text {th }} \& 8^{\text {th }}$ class students of the schools were the participants for the study. Out of total 367 students, 
331 children participated and 36 were absent on the day of data collection. The data was collected on scheduled dates with prior permission from the school authorities.

\section{Study Period}

The data collection was done in the month of August-September 2014.

Variables

Allergies, area of residence, childhood asthma, cooking fuel, cough at night, diet, living in farm, medication, playing, pets, school children, sex of the child, smoking, wheezing, whistling.

\section{Study Tool}

Study participants were asked to fill up the structured questionnaire as scheduled. Questionnaire was based on that used by International Study of Asthma and Allergies in Childhood (ISSAC). ${ }^{22}$ The final questionnaire was a modified version of this questionnaire with addition of questions related to environmental, lifestyle factors and questions regarding severity of asthma based on relevant literature search. The developed questionnaire was translated into local language (Hindi) and pilot tested on a sample of school children. The questionnaire consisted of a total of 24 items. The children were considered to have questionnaire diagnosed asthma if the answer to any of the following question was "yes" viz. Item 3: Has a doctor ever told you that you have asthma?; Item 5: Have you had any wheezing or whistling in the chest in the past 12 months? and Item 7: Have you used medication for the wheezing in last 12 month?

\section{Ethical Considerations}

The study was conducted after the clearance from Institutional Ethical Committee (IEC) of Chirayu Medical College and Hospital (CMCH), Bhopal. Also, consent was sought from school authorities for the study. The head of the school and faculty were explained about the purpose of the study. Before filling up the questionnaire children were guided through questionnaire to fill it up. The questionnaire was filled up under the supervision of Medical Officer of Urban Health and Training Centre situated in Bairagarh; which comes under administrative control of $\mathrm{CMCH}$, Bhopal. Confidentiality of the data of participants of the study was maintained. The newly diagnosed asthmatics and those not receiving treatment were referred to nearby Chirayu Medical College and Hospital for further management.

\section{Statistical Analysis}

Entry of all the data was done on Microsoft office Excel 2007 and was analyzed on statistical package for Social Sciences (SPSS V.S 20.0).

\section{Table 1: Characteristics of study population}

\begin{tabular}{|c|c|}
\hline Variable & School children $(n=331) n(\%)$ \\
\hline \multicolumn{2}{|l|}{ Place of residence: } \\
\hline Rural area/village- & $13(3.9)$ \\
\hline City- & $318(96.1)$ \\
\hline Farm- & $22(6.6)$ \\
\hline \multicolumn{2}{|l|}{ Smoking history of household members: } \\
\hline Present- & $196(59.2)$ \\
\hline Present and inside the house or close to children- & $164(49.5)$ \\
\hline Present but never inside the house or close to children- & $32(9.7)$ \\
\hline Absent- & $135(40.8)$ \\
\hline \multicolumn{2}{|l|}{ Household pets: } \\
\hline Present- & $113(34.1)$ \\
\hline Absent- & $218(65.9)$ \\
\hline \multicolumn{2}{|l|}{ Type of cooking fuel used at home:* } \\
\hline Gas- & $286(86.4)$ \\
\hline Stove/kerosene- & $40(12.1)$ \\
\hline Firewood- & $79(23.86)$ \\
\hline \multicolumn{2}{|l|}{ Allergy: } \\
\hline Present- & $48(14.5)$ \\
\hline Absent- & $283(85.5)$ \\
\hline \multicolumn{2}{|l|}{ Diet: } \\
\hline Vegetarian- & $148(44.7)$ \\
\hline Mixed(vegetarian + non-vegetarian)- & $183(54.3)$ \\
\hline \multicolumn{2}{|l|}{ Family history of asthma: } \\
\hline Yes & $56(16.9)$ \\
\hline No & $275(83.1)$ \\
\hline
\end{tabular}

${ }^{*}$ Total percentage does not equal 100, as more than one type of cooking fuel is used by each household. 


\section{RESULTS}

\section{Study population}

The study included 331 school going children with boys -163 (49.2\%) and girls -168 (50.8\%).

The mean age of study subjects was 13.2 years with a range of $12-17$ years.

\section{Characteristics of study population}

Table- 1 shows the characteristics of the study population. Of 331 children, $96.1 \%$ of the children live in city (urban area), while only $6.6 \%$ lived in farms; $59.2 \%$ had smoking household members, of whom an alarming $49.5 \%$ were exposed to passive smoke at home. $34.1 \%$ children were having pets (dog, cat, goat, cow /buffalo) at home. Majority of households ( $\mathrm{N}=331,86.4 \%$ ) used gas for cooking, with or without other types of fuel. $23.86 \%$ used firewood for cooking.

$14.5 \%$ children were allergic to one or other substances. $44.7 \%$ children were vegetarian and

$54.3 \%$ (rest all) were having a mixed diet (i.e. vegetarian + non-vegetarian diet). $16.9 \%$ children reported history of asthma in the family members.

\section{Prevalence of asthma}

Table 2 depicts prevalence of asthma among school children by various criteria viz. already diagnosed by the physician, asthma like symptoms (wheezing and whistling) and use of asthma medication in last 12 months. There were 46 students out of the total who answered "yes" to any of the above criteria based questions. Thus, the prevalence of ques- tionnaire diagnosed asthma came out to be $13.9 \%$. Out of these $40(87 \%)$ were newly detected asthmatics by the study questionnaire, excluding those already diagnosed by the physician viz. $6(1.8 \%)$. Out of the total asthmatics $44(13.3 \%)$ children reported wheezing and/or whistling in past 12 months and $9(2.7 \%)$ children used medication for wheezing and/or whistling in past 12 months. The prevalence ratio of Male: Female came out to be 1:1.55.

\section{Severity of symptoms among asthma patients}

Table-3 shows the analysis of severity of symptoms among asthmatic children 11 children (23.9\%) had experienced 4 or more asthma attacks in past 12 months; 25 children (54.37\%) suffered limitation of sporting activities at school and same proportion shows limitation of activities at home; 6 children (13.04\%) had visited an emergency department in the past 12 months.

\section{Risk factors associated with asthma}

Table-4 shows the association of risk factors with asthma. With univariate and multivariate analysis, following variables were tested for association with asthma: sex, place of residence, history of asthma, smoking members in household, history of allergy, pets in household and type of diet. With univariate as well as multivariate analysis, out of these variables family history of asthma, history of allergy and presence of cough without cold showed a statistically significant association. Multivariate analysis shows significant association of asthma with family history of asthma, history of allergy.

Table 2: Prevalence of asthma

$\begin{array}{cc}\text { Variable } & \text { School children with asthma (N=331) } \mathbf{n}(\%) \\ \text { Physician diagnosed asthma- } & 6(1.8) \\ \text { Wheezing or whistling in past 12 months- } & 44(13.3) \\ \text { Medication taken for wheezing and whistling in past 12 months- } & 9(2.7) \\ \text { Answer "yes" to any of the above variable (prevalence of questionnaire } \\ \text { diagnosed asthma) }\end{array}$

Table 3: Severity of symptoms among asthmatic children

\begin{tabular}{|cc|}
\hline Variable & Questionnaire diagnosed asthma patients (N1=46) n (\%) \\
\hline Four or more asthma attacks in past 12 months- & $11(23.9)$ \\
Limitation of sporting activities at school- & $25(54.37)$ \\
Limitation of activities at home- & $25(54.37)$ \\
Visits to emergency department in past 12 months- & $6(13.04)$
\end{tabular}

Table 4: Association of various risk factors with asthma by univariate and multivariate analysis in the study population

\begin{tabular}{ccccc} 
Variable & \multicolumn{2}{c}{ Univariate analysis } & \multicolumn{2}{c}{ Multivariate analysis } \\
Sex & p value & OR $(95 \% \mathrm{Cl})$ & p value & aOR $(95 \% \mathrm{Cl})$ \\
Place of residence & 0.139 & $1.611(0.8529-3.043)$ & .977 & $1.011(0.497-2.056)$ \\
Residence in farm & 0.5706 & $0.5212(0.1379-1.97)$ & .225 & $0.424(0.106-1.697)$ \\
Passive smoking at home & 0.7777 & $1.413(0.4558-4.378)$ & .499 & $1.542(0.439-5.419)$ \\
Family history of asthma & 0.6888 & $0.8794(0.4688-1.65)$ & .523 & $1.249(0.631-2.472)$ \\
History of allergy & 0.00009362 & $3.698(1.86-7.353)$ & .001 & $3.740(1.755-7.972)$ \\
Pets in household & 0.0009416 & $3.23(1.567-6.655)$ & .005 & $3.054(1.397-6.675)$ \\
Type of diet & 0.3649 & $0.7288(0.3669-1.448)$ & .568 & $0.568(0.270-1.193)$ \\
Cough without cold & 0.1568 & $0.6378(0.3411-1.192)$ & .323 & $1.407(0.715-2.769)$
\end{tabular}


Patil et al.: Prevalence of asthma in school going children.

\section{DISCUSSION}

The prevalence of asthma in present study was found to be $13.9 \%$ among school children. The prevalence of asthma as found in various studies ranges from $3.5 \%$ to $29.5 \% .^{1-21}$ Similar are the prevalence rates of asthma in school children in the study quoted by Chhabra et $a l^{11}(15.7 \%)$ and in an another study by Mistry ${ }^{17}(12.5 \%)$. Various studies on asthma in school children show variation in prevalence in rural and urban areas, ${ }^{4,6,10,14,15,18,19}$ the prevalence being higher in urban children. This may be due to urban air pollution because of industries, automobiles, allergens etc. Some of the studies have shown prevalence lower than the present study in urban setting., ${ }^{4,15,1720}$ The possible reason for the lower prevalence could be use of different definition for defining the prevalence, random selection of the samples, different sample size, different age group, different year of study, urbanization which could mean a number of lifestyle changes such as dietary habits, pollution, crowding etc.

In contrast to other studies, ${ }^{16,18,19,20}$ the present study shows female predominance (male: female asthma ratio- 1:1.5) for the prevalence of asthma. This fact needs to be investigated with further studies.

A statistically significant association found between asthma and family history of asthma has also been documented by other studies. ${ }^{11,14,16,18,20,21}$ A significant association was found between history of allergy and asthma in the present study. Similar findings has been reported in the study by Dhabadi et al. ${ }^{6}$ History of cough without cold was strongly associated with asthma by both multivariate and univariate analysis, which shows similarities with other studies. ${ }^{4,16,19}$ Other studies have also shown association of asthma with passive smoking, pets at home, environmental tobacco smoke, absence of smoke outlet ${ }^{10,13,16,21}$ which has not been found statistically significant in this study.

Around $50 \%$ of the asthmatics have limited sporting activity as well as activity at home, this shows poor control of asthma incapacitating to children. The poor control of asthma may be due to poor access to health services, lack of awareness or inadequate training in diagnosing asthma by the physician.

\section{CONCLUSION}

With prevalence of $13.9 \%$ of asthma in school children, in the present study around $87 \%$ remained undetected. This confirms to the higher trend of asthma prevalence as depicted by various studies. Multivariate analysis shows significant association of asthma with family history of asthma, history of allergy and cough without cold. Prevalence of asthma was seen more among the girls as compared to boys. This study also demonstrated need to control asthma in order to improve quality of life in children. Thus, the study underscores need for screening of asthma in school for early diagnosis and better asthma management. Moreover, Children and parents need to be educated about asthma symptoms and its care.

\section{SOURCES OF SUPPORT}

Indian Council of Medical Research, STS Project, 2014

\section{ACKNOWLEDGEMENT}

Indian Council of Medical Research, STS Project, 2014

\section{CONFLICT OF INTEREST}

Nil

\section{ABBREVIATION USED}

ISAAC: International Study of Asthma and Allergies in Childhood; EIB: exercise induced bronco spasm; IEC: Institutional Ethical Committee; CMCH: Chirayu Medical College and Hospital; SPSS: Statistical Package for Social Sciences; OR: Odds Ratio; aOR: adjusted Odds Ratio; STS Short Term Studentship.

\section{REFERENCES}

1. Frank TL, Frank PI, McNamee R, Wright T, Hannaford P, Morrison J, et al. Assessment of a simple scoring system applied to a screening questionnaire for asthma in children aged $5 \pm 15$ yrs. Eur Respir J. 1999;14:1190-7.

2. Pal R, Dahal S, Pal S. Prevalence of Bronchial Asthma in Indian Children. Indian J Community Med. 2009;34(4): 310-6.

3. Mehta P. Asthma in school going children. Indian Pediatrics. 2002;39:731-8.

4. Chakravarthy S, Singh RB, Swaminathan S, Venkatesan P. Prevalence of asthma in urban and rural children in Tamil Nadu. Natl Med J India. 2002;5(5):260-3.

5. Paramesh H. Epidemiologyof asthma in india. Indian J Pediatr. 2002;69(4):30912.

6. Dhabadi BB, Athavale A, Meundi A, Rekha R, Suruliraman M, Shreeranga A, et al. Prevalence of asthma and associated factors among schoolchildren in rural South India. Int J Tuberc Lung Dis. 2012;16(1):120-5.

7. Hussein SE, Ahmed MA. Prevalence and risk factors of asthma among Wad mednai basic school children, gezira state, Sudan. J Family Community Med. 2005;12(3):145-8

8. Hill RA, Standen PJ, Tattersfield AE. Asthma, wheezing, and school absence in primary schools. Archives of Disease in Childhood. 1989;64:246-51.

9. Leung R, Wong G, Lau J, Ho A, Chan JKW, Choy D, et al. Prevalence of asthma and allergy in Hong Kong schoolchildren: an ISAAC study. Eur Respir J. 1997; 10(2):354-60.

10. Pokharel PK, Kabra SK, Kapoor SK, Pandey RM. Risk factors associated with bronchial asthma in schoolgoing children of rural Haryana. Ind J Pediatr. $2001 ; 68(2): 103-6$

11. Chhabra SK, Gupta CK, Rajpal S, Chhabra P. Prevalence of asthma in school children in Delhi. J Asthma. 1998;3:291-6.

12. Awasthi S, Kalra E, Roy S, Awasthi S. Prevalence and risk factors of asthma and wheeze in school-going children in Lucknow, North India. Ind Pediatr. 2004;41(12):1205-10.

13. Gupta D, Aggarwal AN, Kumar R, Jindal SK. Prevalence of bronchial asthma and association with environmental tobacco smoke exposure in adolescent school children in Chandigarh, north India. J Asthma. 2001;38(6):501-7.

14. Prasad R, Verma SK, Ojha S, Shrivastava VK. A questionnaire based study of bronchial asthma in rural children of lucknow. Indian J Allergy Asthma Immunol. 2007;21(1):15-8

15. Jindal SK, Aggarwal AN, Gupta D, Kashyap S, Chaudhary D. Prevalence of tobacco use among school going youth in north Indian states. Ind J Chest Dis Allied Sci. 2005;47(3):161-6.

16. Pakhale S, Wooldrage K, Manfreda J, Anthonisen N. Prevalence of asthma symptoms in 7th and 8th grade schoolchildren in rural region in India. J Asthma. 2008;45:117-22

17. Mistry R, Wickramasingha N, Ogston $S$, et al. Wheeze and urban variation in south Asia. Eur J Pediatr. 2004;163:145-7.

18. Jain A, Bhat HV, Acharya D. Prevalence of bronchial asthma in rural Indian children: A

19. cross sectional study from South India. The Indian Journal of Pediatrics January. 2010;77(1):31-5.

20. Narayana PP, Prasanna MP, Narahari SR, Guruprasad AM. Prevalence of asthma in school children in rural India. Ann Thorac Med. 2010;5(2):118-9.

21. Behl RK, Kashyap S, Sarkar M. Prevalence of bronchial asthma in school children of 6-13 years of age in Shimla city. Indian J Chest Dis Allied Sci. 2010;52(3):145-8.

22. Kumar GS, Roy G, Subitha L, Sahu SK. Prevalence of bronchial asthma and its associated factors among school children in urban Puducherry, India. J Nat Sci Biol Med. 2014;5(1):59-62.

23. Phase three core questionnaire. International Study of Asthma and Allergies in Childhood. [home page: http://isaac.auckland.ac.nz/index.html ] c2013 [accessed on 20th jan 2014] [around 7 pages]. Available from: http://isaac.auckland.ac.nz/phases/phasethree/corequestionnaire.pdf

Cite this article : Vyankatesh AA, Bharat PS, Kush A. Prevalence of Asthma in School going Children of Semi-Urban Area in the State of Madhya Pradesh. Int J Med. Public Health. 2016; 7(1): 37-40. 